\title{
Different genotypes of Phragmites australis show distinct phenotypic plasticity in response to nutrient availability and temperature
}

\author{
Franziska Eller*, Hans Brix \\ Department of Bioscience, Plant Biology, Aarhus University, Ole Worms Allé 1, DK-8000 Aarhus C, Denmark
}

\section{A R T I C L E I N F O}

\section{Article history:}

Received 19 October 2011

Received in revised form 9 July 2012

Accepted 11 July 2012

Available online 20 July 2012

\section{Keywords:}

Algeria

Clone

Common reed

Denmark

Fitness

Plasticity index

\begin{abstract}
A B S T R A C T
We studied the phenotypic plasticity of physiological and growth traits in two distinct clones of common reed (Phragmites australis (Cav.) Trin. Ex Steud.). Replicates of a clone from Denmark (DK clone) belonging to the European temperate $P$. australis and a clone from Algeria (ALG clone) belonging to the African-Mediterranean gene pool of $P$. australis were grown in phytotrons in a factorial block design at $15^{\circ} \mathrm{C}$ or $25^{\circ} \mathrm{C}$ daytime temperature and high or low fertilization level. Plant growth, tissue nutrient concentrations, photosynthetic pigments and photosynthetic characteristics were measured. Phenotypic plasticity was quantified for the measured traits as plasticity indices in relation to temperature and fertilization. The plasticity index was calculated as the difference between the maximum and the minimum mean value divided by the maximum mean value of a parameter within a treatment. The functional significance of the plasticity and its contribution to plant fitness was assessed by correlation of the plant traits to plant biomass as a proxy for fitness.

The DK clone responded much more to temperature than the ALG clone, which responded more to fertilization, and both clones responded to high fertilization with lower allocation of biomass to roots and rhizomes. The ALG clone had a higher nutrient demand due to its large and fast biomass development. Hence, for most traits, the calculated plasticity indices for fertilization were highest for the ALG clone, especially within photosynthetic parameters and pigments, and the plasticity indices for temperature were highest for the DK clone, especially within growth parameters. In both clones, photosynthetic pigments, biomass allocation to leaf blades and rhizomes, the shoot:root ratio as well as leaf and shoot production rates were highly correlated to fitness. These traits also had a relatively high degree of plasticity, indicating a functional significance of plasticity, but several traits that showed high plasticity did not correlate with fitness (e.g. $P_{\max }$ ). We conclude that the responses of the two contrasting $P$. australis genotypes to temperature and fertilization are genetically determined and related to the climatic conditions at the site of their origin. Although phenotypic plasticity per se is not a precondition for plant fitness, the genetically determined differences in the degree of phenotypic plasticity of distinct $P$. australis genotypes to temperature and nutrient availability affect fitness and may influence how the genotypes will respond to global environmental change.
\end{abstract}

(c) 2012 Elsevier B.V. All rights reserved.

\section{Introduction}

Plants of the same species with several distinct genotypes are capable of growing in different habitats of high environmental heterogeneity. As a consequence, they may possess a high phenotypic variation (Lehmann and Rebele, 2005; Sultan, 1995). Phenotypic plasticity is generally defined as the capacity of a genotype to produce distinct phenotypes when exposed to different environmental conditions, and phenotypic plasticity has been suggested important for adaptation to temporal environmental changes and spatial heterogeneity (Bradshaw, 1965; Sultan, 2000). Adaptive

\footnotetext{
* Corresponding author. Tel.: +45 87156574; fax: +45 87154302.

E-mail address: franziska.popko@biology.au.dk (F. Eller).
}

phenotypic plasticity is the phenotypic response to an environment that enhances plant performance. This phenotypic variation is often considered to be a functional response maximizing fitness in the particular environment (Sultan, 1995). Sudden environmental changes might put species lacking sufficient plasticity at risk of extinction, not being able to withstand unfavorable conditions (Coleman et al., 1994; Sultan, 2000).

Plasticity is trait-specific, as genotypes are not plastic but can disclose plastic traits when exposed to contrasting environmental conditions. An example is a rapid change in growth characteristics and morphology that can provide greater access to limiting resources (Grime and Mackey, 2002; Haraguchi, 1993). Thus, to compensate for biomass reduction occurring under resource limitation, plants increase biomass allocation to roots in low-nutrient soils. Such functional plasticity can allow the genetic individual to 
grow and reproduce successfully in different environments (Sultan, 2000).

Plants encounter multiple environmental factors and the effects on plant growth often interact. Nutrient availability and temperature are key environmental forces to which plants respond phenotypically. For instance, simulated warming changed the biomass allocation among developmental stages and types of ramets of Carex bigelowii as well as the nutrient concentrations in the aboveground tissues (Jonsdottir et al., 2005). Also, in Calamagrostis epigejos, the highest plasticity was found for the belowground biomass allocation as an adjustment to variable soil fertility (Lehmann and Rebele, 2005). In spring and winter wheat a change of the growth temperature resulted in the adjustment of the root:shoot ratio and the carbohydrate content (Equiza and Tognetti, 2002).

Phenotypic plasticity has been investigated in both annual and perennial plants (Dong et al., 1996; Funk, 2008; Sultan, 1995). Clonal perennials reproduce both vegetatively and by sexual reproduction. By clonal spread, the plants are able to respond rapidly to environmental heterogeneity whereas sexual reproduction enables the maintenance of genetic variability for natural selection. Santamaria (2002) pointed out that the generality of broad plastic responses, promoted by the clonal growth of aquatic vascular plants, favors a wide spatial distribution.

The common reed (Phragmites australis) is a dominant clonal wetland plant with a worldwide geographical distribution. The occurrence of this perennial grass ranges from cold temperate to tropical regions, in oligotrophic as well as eutrophic habitats. It relies both on sexual and vegetative spreading, with annual shoots emerging from perennial horizontal and vertical rhizomes (Brix, 1999; Haslam, 1968). Several studies have shown that $P$. australis has a high genetic variability both between and within populations, which is augmented by its clonal growth form and cosmopolitan distribution (Brix, 1999; Clevering and Lissner, 1999; Hansen et al., 2007; Kuhl et al., 1999; Rolletschek et al., 1999). Also, genetically determined differences in the timing of flowering, length of growing seasons, biomass allocation and morphology have been found in different $P$. australis clones from a latitudinal gradient (Bastlova et al., 2006; Clevering et al., 2001). These differences have been proposed to have developed as adaptations to growth in various climatic habitats (Clevering et al., 2001; Hansen et al., 2007). However, the significance of genetic determinacy and external constraints for $P$. australis stand structure and growth may vary from habitat to habitat (Engloner, 2009). In P. australis clones growing adjacent to each other, clone-specific differences in morphology and physiological parameters have been found, even after transplantation to a common environment, indicating that different genotypes may respond differently to changing site conditions, and that different genotypes may use different ecophysiological strategies (Rolletschek et al., 1999). Also, a strong effect of the geographical gradient on the growth and phenology of different P. australis populations has been found by Bastlova et al. (2004). $P$. australis has been shown to be a highly plastic plant in several studies. Vretare et al. (2001) found that $P$. australis exhibited phenotypic plasticity as a functional response to different water depths, and Bellavance and Brisson (2010) reported that $P$. australis had a competitive advantage over Typha sp. due to its high morphological plasticity. Moreover, Clevering (1999) showed that clones of $P$. australis originating from infertile habitats were less plastic than those from fertile and eutrophicated habitats.

Although P. australis is one of the most intensively studied wetland plants, to our knowledge, a comparison and quantification of the phenotypic plasticity of distinct genotypes, and an assessment of the functional significance of their plastic responses, has never been made. In this study, the plasticity of physiological and growth traits in two phylogeographically distinct clones of $P$. australis subjected to different growth temperatures and nutrient availabilities was measured. The effects of growth temperature and nutrient availability on the contribution of plant trait plasticity to fitness were investigated in order to assess the extent to which differences in genotypes may lead to a different functional significance of plasticity. We hypothesize that the genetic background of the clone determines which plant traits contribute mainly to fitness in different environments.

\section{Materials and methods}

\subsection{Plant material and experimental setup}

The plants used in this study were chosen from a large collection of live $P$. australis clones, kept in a common environment at Aarhus University, Denmark $\left(56^{\circ} 13^{\prime} \mathrm{N} ; 10^{\circ} 07^{\prime} \mathrm{E}\right)$, for at least five years prior to the study. Each clone of the collection is the progeny of a single plant and represents a different genotype. Two clones were compared based on their phylogeographic relationship: a clone from a coastal stand close to Aarhus, Denmark (56 $12^{\prime} \mathrm{N} ; 10^{\circ} 29^{\prime} \mathrm{E}$ ) (DK clone), and a clone from an oasis in the Sahara desert close to Guebbour, Algeria $\left(28^{\circ} 29^{\prime} \mathrm{N} ; 6^{\circ} 41^{\prime} \mathrm{E}\right.$ ) (ALG clone). The DK clone possesses the alleles of the European temperate P. australis, whereas the ALG clone belongs to the African-Mediterranean gene pool of $P$. australis. The differences between the clones are therefore assumed to be driven by different evolutionary pressures in their native distribution ranges. The phylogeographic groups within $P$. australis were identified and described in Lambertini et al. (2006).

The clones were propagated by layering of shoots horizontally in shallow water for five weeks to initiate adventitious shoot growth at the stem nodes. When adventitious shoots were $15-20 \mathrm{~cm}$ high and had developed roots, the stems were cut at both sides of the nodes and the resulting genetically identical replicates were planted in $3.5 \mathrm{~L}$ pots containing a commercial peat. Each potted plant was placed in its own outer container to allow separate treatment. The plants were then placed in two $2.0 \mathrm{~m} \times 0.8 \mathrm{~m} \times 1.7 \mathrm{~m}$ $(L \times W \times H)$ indoor growth cabinets (BIO 2000S, Weiss Umwelttechnik $\mathrm{GmbH}$, Lindensruth, Germany) at a relative air humidity of $65 \%$, a light:dark cycle of $16: 8 \mathrm{~h}$, and at an irradiance of approximately $400 \mu \mathrm{mol} \mathrm{m}^{-2} \mathrm{~s}^{-1}$ (PAR) at the base of the plants, provided by metal halide bulbs. After an acclimatization period of two weeks with a $20^{\circ} \mathrm{C}: 17^{\circ} \mathrm{C}$ day:night temperature cycle, the plants were distributed between two growth cabinets: one with a $15^{\circ} \mathrm{C}: 12^{\circ} \mathrm{C}$ day:night temperature cycle (Low Temp treatment; $15^{\circ} \mathrm{C}$ ), the other with a $25^{\circ} \mathrm{C}: 22^{\circ} \mathrm{C}$ day:night temperature cycle (High Temp treatment; $\left.25^{\circ} \mathrm{C}\right)$. The ability of the growth cabinets to control the air temperature and relative humidity was generally better than $0.5^{\circ} \mathrm{C}$ and $3 \% \mathrm{RH}$, respectively. However, during photoperiods, gradients in temperature and humidity develop in the chambers. Hence, plants were rotated at random in each of the growth chambers once a week to minimize undesired chamber effects.

The plants were fertilized twice per week with $250 \mathrm{~mL}$ of a nutrient solution prepared from tap water containing either $1 \%$ (High Fert treatment) or $0.1 \%$ (Low Fert treatment) of a commercial macronutrient solution (Pioner NPK Makro 10-4-25+ Mg, Brøste, Denmark). The $1 \%$ onutrient solution contained (in $\mathrm{mM}$ ): $6.1 \mathrm{NO}_{3}$, $0.9 \mathrm{NH}_{4}, 1.3 \mathrm{P}, 6.5 \mathrm{~K}, 1.8 \mathrm{Mg}$ and $1.8 \mathrm{~S}$. Micronutrients were supplied at the same level (in $\mu \mathrm{M}$ : $0.02 \mathrm{~B}, 2.2 \mathrm{Cu}, 24 \mathrm{Fe}, 9.1 \mathrm{Mn}, 0.5$ Mo and $2.8 \mathrm{Zn}$ ) in all treatments from a commercial micronutrient stock solution (Pioner Mikro + Fe, Brøste, Denmark). The pH was adjusted to $\mathrm{pH} 6.7$ and additional iron (approximately $0.6 \mathrm{mM}$ of $\mathrm{Fe}(\mathrm{II}) \mathrm{SO}_{4}$ ) was added right before every fertilization. Between fertilizations, the plants were watered with demineralized water. The plants were placed such as to largely avoid shading by adjacent taller plants. 
The experimental setup was a $2 \times 2 \times 2$ factorial design with the factors being "Clone" (DK clone versus ALG clone), "Temperature" (Low Temp: $15^{\circ} \mathrm{C}$ versus High Temp: $25^{\circ} \mathrm{C}$ ) and "Fertilization" (Low Fert: $0.1 \%$ versus High Fert: $1 \%$ ) with six replicates in each treatment combination. The experiment was run for $76 \mathrm{~d}$ after the acclimatization period.

\subsection{Plant growth and tissue analysis}

Numbers of shoots and leaves per plant were counted weekly. The number of leaves per plant included all fully developed leaves. Absolute shoot and leaf production rates were determined as the difference between the final and the initial number of shoots and leaves, respectively, divided by the growth period in days. At the final harvest, plants were fractionated into leaf blades, leaf sheaths, stems, roots and rhizomes, the fractions dried to constant dry mass at $80^{\circ} \mathrm{C}$ and then weighed. Biomass allocation was calculated as the ratio of the dry mass of the respective plant part to final dry mass. The ratio of aboveground plant parts to belowground plant parts (hereafter shoot:root ratio) was determined.

Total nitrogen $(\mathrm{N})$ was analyzed in $1.5-3.5 \mathrm{mg}$ of ground material with a CN analyzer (Fisons Instruments, Model NA2000, Italy) and expressed on a \% dry mass basis. The concentrations of $\mathrm{P}$ and $\mathrm{K}$ were analyzed by inductively coupled plasma emission spectrometry (Perkin Elmer Plasma II, CT, USA) after digestion of ground material in $\mathrm{HNO}_{3}-\mathrm{H}_{2} \mathrm{O}_{2}$ in a microwave oven (Multiwave 3000, Anton Paar $\mathrm{GmbH}$, Austria).

The fresh leaf blade of the youngest fully developed leaf, which was also used for photosynthesis measurement, was scanned with an area meter (Model 3100, LI-COR, USA) and, after freeze drying, weighed to determine the specific leaf area (SLA; the ratio of leaf area to leaf dry mass). Hereafter, concentrations of total chlorophyll $\left(\mathrm{Chl}_{\mathrm{a}}\right.$ and $\left.\mathrm{Chl}_{\mathrm{b}}\right)$ and total carotenoids in the same leaf were analyzed after extraction with $96 \%$ ethanol by photospectrometry according to Lichtenthaler (1987).

\section{3. $\mathrm{CO}_{2}$-exchange}

After approximately six weeks of experimental growth, photosynthetic gas exchange parameters were measured with an ADC LCA-4 infrared gas analyzer (IRGA) equipped with a Leaf Microclimate Control System (ADC BioScientific Ltd., UK). The PLC-4 leaf chamber was air conditioned at the respective growth temperature and placed on a tripod to ensure stability during readings. The leaf chamber was supplied with ambient air from outside the building using an air pump. Light was supplied from a white halogen source (Portable Light Unit, PLU-002, ADC BioScientific Ltd., UK) at an irradiance of approximately $1500 \mu \mathrm{mol} \mathrm{m}^{-2} \mathrm{~s}^{-1}$ (PAR). Light response curves were prepared by measuring net $\mathrm{CO}_{2}$-assimilation at $1500 \mu \mathrm{mol} \mathrm{m}^{-2} \mathrm{~s}^{-1}$ to estimate the maximum light-saturated rate of photosynthesis $\left(P_{\max }\right)$, and at the linear part of the light response curve at $110,75,40,20$ and $5 \mu \mathrm{mol} \mathrm{m}^{-2} \mathrm{~s}^{-1}$. The irradiance was controlled by placing neutral filters between the light source and the leaf chamber. The measurements began with the highest irradiance $\left(1500 \mu \mathrm{mol} \mathrm{m}^{-2} \mathrm{~s}^{-1}\right)$ and the readings were logged after a stable assimilation rate was reached. $P_{\max }$ was calculated as the average of five readings at $1500 \mu \mathrm{mol} \mathrm{m}^{-2} \mathrm{~s}^{-1}$. The apparent quantum yield $(\phi)$, the dark respiration rate $\left(R_{\mathrm{d}}\right)$ and the light compensation point $\left(I_{C}\right)$ were estimated from the linear part (5-110 $\mu \mathrm{mol} \mathrm{m}^{-2} \mathrm{~s}^{-1}$ PAR) of the light response curves using linear regression analysis. Photosynthetic nitrogen-use efficiency (PNUE) was calculated as the ratio of $P_{\max }$ to leaf $\mathrm{N}$ concentration.

$\mathrm{CO}_{2}$-response curves were prepared by measuring net $\mathrm{CO}_{2}$ assimilation at a range of $\mathrm{CO}_{2}$ levels in the air supplying the leaf chamber at an irradiance of $1500 \mu \mathrm{mol} \mathrm{m}^{-2} \mathrm{~s}^{-1} \cdot \mathrm{CO}_{2}$ levels were enriched by mixing atmospheric air with synthetic air containing
2000 ppm $\mathrm{CO}_{2}$ (ADC Gas Mixer, The Analytical Development Co., Ltd., Hoddesdon, England). The desired $\mathrm{CO}_{2}$ level was controlled by the microclimate control system of the IRGA. Measurements began at the highest $\mathrm{CO}_{2}$ level (800 ppm) and, after logging, the $\mathrm{CO}_{2}$ level was lowered to approximately $400,200,50$ and $<3 \mathrm{ppm}$. To achieve a $\mathrm{CO}_{2}$ level of $<3 \mathrm{ppm}$ in the reference air, a $\mathrm{CO}_{2}$ scrubbing filter was fitted into the airflow line, before the air was passed into the leaf chamber. Maximum carboxylation rates $\left(V_{\mathrm{cmax}}\right)$ were estimated from the initial part of the $\mathrm{CO}_{2}$-response curves $\left(C_{i}<250 \mathrm{ppm}\right)$ following Dubois et al. (2007) based on the photosynthesis model of Farquhar et al. (1980). The $\mathrm{CO}_{2}$ compensation point $(\Gamma)$ was estimated using linear regression analysis.

\subsection{Chlorophyll fluorescence}

The effective quantum yield of PSII in dark-incubated leaves $\left(F_{\mathrm{v}} / F_{\mathrm{m}}\right)$ was measured in dark-acclimated leaves with a Portable Chlorophyll Fluorometer (PAM-2000, Walz Mess- und Regeltechnik, Germany). Leaves were darkened for minimum 15 min with a leaf clamp prior to measurement.

\subsection{Plasticity indices}

Plasticity indices (PIs) were calculated for the measured parameters according to Valladares et al. (2006) to compare the degree of plasticity among the clones as a response to temperature and fertilization, respectively. The index ranges from zero (no plasticity) to one (maximum plasticity) and is calculated within each treatment (either temperature or fertilization) as follows:

$\mathrm{PI}=\frac{\text { maximum mean }- \text { minimum mean }}{\text { minimum mean }}$

PIs were calculated for all physiological and growth parameters that were not significantly affected by the interaction term "Temp $\times$ Fert".

\subsection{Statistical analyses}

All statistical analyses were conducted using the software Statgraphics Centurion XVI (Statpoint Technologies, Inc., VA, USA).

A rotated principal components analysis (PCA) was conducted on all results. The number of factors was restricted to three, and the factor scores after Equimax rotation were used for interpretation of the data variability.

Data were also analyzed by three-way (Clone $\times$ Temp $\times$ Fert) analysis of variance (ANOVA). The third-order interaction term was suppressed. Data were tested for variance homogeneity using Levene's test and, if necessary, log-transformed to ensure homogeneity of variance. Multiple levels of main effects were compared by Bonferroni multiple range tests at the $5 \%$ significance level.

Biomass parameters were used as a proxy for plant fitness, as reproductive measures are difficult to obtain in short term studies. The "fitness factor" for each clone was estimated by a PCA, which combined the masses of all single plant fractions (leaf blades, leaf sheaths, stems, roots, rhizomes) and the final biomass into a single parameter. There was only one principle component extracted, its values (factor scores) were used in the correlation analysis. This ensured the incorporation of all plant parts into the fitness estimate.

To assess the functional significance of plasticity for fitness, Pearson product moment correlation coefficients were calculated between the individual plant parameters and the fitness factor scores across all four treatments for each clone by multiple-variable analysis. Correlation coefficients were calculated for the same parameters as plasticity indices.

Plasticity indices were analyzed by two-way (Clone $\times$ Treatment) ANOVA, where "Treatment" was either 




Fig. 1. Mean final biomass (g DM) of two P. australis genotypes (DK, DK clone; ALG, ALG clone) grown at $15^{\circ} \mathrm{C}$ and $25^{\circ} \mathrm{C}$ and at low and high fertilization, respectively.

Temperature or Fertilization. PIs were log-transformed to achieve homogeneity of variance.

One replicate of the DK clone from the Low Temp and Low Fert treatment grew poorly and died before the end of the experiment. Hence, it was removed from all statistical analyses.

\section{Results}

Fertilization and temperature affected growth and physiology of the two clones, and the responses of the clones differed for several of the measured parameters as shown by the significant interaction terms in the ANOVA (Table 1).

\subsection{Plant growth and biomass allocation}

Shoot and leaf production rates differed between clones and were significantly affected by fertilization and temperature (Table 2). Fertilization stimulated shoot and leaf production rates of both clones, but the DK clone responded much stronger to elevated temperature than the ALG clone, as shown by the significant Clone $\times$ Temp interaction in the ANOVA.

The ALG clone had a 3-5 times higher final biomass than the DK clone and a higher shoot:root ratio. The shoot:root ratio was highest at high fertilization and the DK clone responded more to temperature than the ALG clone (Fig. 1 and Table 2).

Biomass allocation differed between the clones depending on temperature, as shown by the significant Clone $\times$ Temp interactions in the ANOVAs. The DK clone allocated more biomass to the aboveground plant parts at $25^{\circ} \mathrm{C}$ and more to the belowground plant parts at $15^{\circ} \mathrm{C}$, whereas temperature had no effect on biomass allocation of the ALG clone. For both clones, high fertilization decreased allocation to roots and rhizomes. However, allocation to roots of the DK clone was not affected by fertilization at low temperature (Temp $\times$ Fert interaction). In addition, allocation to stems was not affected by fertilization in either of the clones (Fig. 2).

\subsection{Photosynthesis, fluorescence and photosynthetic nitrogen-use efficiency (PNUE)}

The two clones differed significantly in most of the measured parameters. The light-saturated rate of photosynthesis $\left(P_{\max }\right)$, the dark respiration rate $\left(R_{\mathrm{d}}\right)$ and the maximum quantum yield of PSII $\left(F_{\mathrm{v}} / F_{\mathrm{m}}\right)$ were affected by a significant Clone $\times$ Fert interaction, as the ALG clone had higher values at high fertilization, whereas fertilization did not affect these parameters in the DK clone. The DK clone had a higher apparent quantum yield $(\phi)$ and maximum rate of Rubisco carboxylation $\left(V_{\mathrm{cmax}}\right)$ and a lower light compensation point $\left(I_{\mathrm{C}}\right)$ than the ALG clone (Table 3$)$. A Clone $\times$ Temp



Fig. 2. Biomass allocation (\% of final biomass) to fractions of two $P$. australis genotypes (DK, DK clone; ALG, ALG clone) grown at $15^{\circ} \mathrm{C}$ and $25^{\circ} \mathrm{C}$ and at low and high fertilization, respectively.

interaction affected the $\mathrm{CO}_{2}$ compensation point $(\Gamma)$, as the DK clone responded more to temperature than the ALG clone. Temperature also affected $V_{\mathrm{cmax}}$ and $F_{\mathrm{v}} / F_{\mathrm{m}}$ (highest at $25^{\circ} \mathrm{C}$ ) and $P_{\max }$ (highest at $15^{\circ} \mathrm{C}$ ). Fertilization affected $I_{\mathrm{C}}$ which was highest for both clones at high fertilization. The PNUE was significantly higher in the ALG clone than in the DK clone, but unaffected by fertilization or temperature (Table 3 ).

\subsection{SLA, photosynthetic pigments, $N, P$ and $K$}

The specific leaf area (SLA) was affected by a Clone $\times$ Temp interaction. At $25^{\circ} \mathrm{C}$, SLA of the ALG clone was significantly higher than at $15^{\circ} \mathrm{C}$, while there was no temperature effect on the DK clone. Overall, the ALG clone had a higher SLA than the DK clone (Table 4).

The leaves of the DK clone contained higher concentrations of photosynthetic pigments than the leaves of the ALG clone. A Clone $\times$ Fert interaction was observed for $\mathrm{Chl}_{\mathrm{a}}, \mathrm{Chl}_{\mathrm{b}}$ and the $\mathrm{Chl} \mathrm{a} / \mathrm{b}$ ratio as well as the $\mathrm{Chl} /$ carotenoid ratio, since only the ALG clone had higher values at high fertilization. Furthermore, a Clone $\times$ Temp interaction affected $\mathrm{Chl}_{\mathrm{b}}$, total carotenoids (the DK clone had higher values at $25^{\circ} \mathrm{C}$ ), the $\mathrm{Chl} \mathrm{a/b}$ ratio (the DK clone had higher values at $15^{\circ} \mathrm{C}$ ) and the $\mathrm{Chl} /$ carotenoid ratio (the ALG clone responded more to temperature than the DK clone) (Table 4).

The leaf $\mathrm{N}$ concentrations were higher in the DK clone than in the ALG clone and higher at $15^{\circ} \mathrm{C}$ than at $25^{\circ} \mathrm{C}$. The High Fert treatment only resulted in higher tissue $\mathrm{N}$ concentration in the ALG clone (Clone $\times$ Fert interaction). The leaf concentrations of $\mathrm{K}$ and $\mathrm{P}$ were affected by a Clone $\times$ Temp interaction, where the DK clone had higher leaf $\mathrm{K}$ and $\mathrm{P}$ concentrations at $25^{\circ} \mathrm{C}$ than the ALG clone. The leaf $\mathrm{K}$ and $\mathrm{P}$ concentrations generally were higher at high fertilization (Table 5).

\subsection{Principal components analysis, phenotypic plasticity and fitness correlation}

All measured parameters were simplified into three major principal components describing the variation in the responses of the plants to the treatments (Table 6). The first principal component (PC1) explained the largest percentage of the variation $(36.4 \%)$ and had high loadings for the shoot and leaf production rates, biomass allocation to all plant fractions except stems, the shoot:root ratio, SLA, leaf $\mathrm{K}$ content and $\Gamma$ and was interpreted as "growth factor". Principal component 2 (PC2) explained an additional 26.7\% of the variation and had high loadings for all analyzed photosynthetic pigments and pigment ratios, leaf $\mathrm{N}$ and $\mathrm{P}$ concentrations, $\phi$, PNUE and biomass allocation to stems. It was interpreted as 
Table 1






quantum yield of PSII; $V_{\mathrm{cmax}}$, maximum carboxylation rate of Rubisco; SLA, specific leaf area; PNUE, photosynthetic nitrogen-use efficiency.

\begin{tabular}{|c|c|c|c|c|c|c|}
\hline \multirow[t]{2}{*}{ Parameter } & \multicolumn{3}{|l|}{ Main factors } & \multicolumn{3}{|l|}{ Interactions } \\
\hline & Clone d.f. $=1$ & Temp d.f. = 1 & Fert d.f. $=1$ & Clone $\times$ Temp d.f. $=1$ & Clone $\times$ Fert d.f. $=1$ & Temp $\times$ Fert d.f. $=1$ \\
\hline Shoot production rate & $9.3^{* *}$ & $101.6^{* * *}$ & $8.9^{* *}$ & $4.9^{*}$ & 1.2 & 0.2 \\
\hline Leaf production rate & $18.6^{* * *}$ & $343.8^{* * *}$ & $13.2^{* * *}$ & $38.9^{* * *}$ & 3.2 & 1.2 \\
\hline Shoot:root ratio & $5.5^{*}$ & $63.6^{* * *}$ & $4.8^{*}$ & $29.0^{* * *}$ & 0.0 & 0.8 \\
\hline Leaf blade allocation & $9.6^{* *}$ & $623.1^{* * *}$ & $18.9^{* * *}$ & $213.9^{* * *}$ & 0.0 & 0.0 \\
\hline Leaf sheath allocation & $27.4^{* * * *}$ & $21.4^{* * *}$ & $5.8^{*}$ & $42.4^{* * *}$ & 1.0 & 0.1 \\
\hline Stem allocation & $384.6^{* * *}$ & $11.6^{* *}$ & 1.1 & $14.8^{* * *}$ & 1.4 & 0.5 \\
\hline Root allocation & $74.0^{* * *}$ & $151.8^{* * *}$ & $16.9^{* * *}$ & $121.7^{* * *}$ & 0.0 & $4.7^{*}$ \\
\hline Rhizome allocation & $27.9^{* * * *}$ & $97.8^{* * *}$ & $5.4^{*}$ & $42.8^{* * *}$ & 1.2 & 0.2 \\
\hline$\phi$ & $7.5^{* *}$ & 0.0 & 2.1 & 0.5 & 3.8 & 3.8 \\
\hline$P_{\max }$ & $4.7^{*}$ & $14.8^{* * *}$ & 3.8 & 0.3 & $8.8^{* *}$ & 0.0 \\
\hline$R_{\mathrm{d}}$ & $7.9^{* *}$ & 0.7 & $14.5^{* * *}$ & 1.4 & $7.7^{* * *}$ & 1.1 \\
\hline$I_{\mathrm{c}}$ & $11.8^{* *}$ & 2.1 & $8.6^{* *}$ & 0.9 & 3.1 & 0.3 \\
\hline$\Gamma$ & 0.9 & $91.1^{* * *}$ & 0.0 & $4.1^{*}$ & 0.1 & 0.2 \\
\hline$F_{\mathrm{v}} / F_{\mathrm{m}}$ & $4.7^{*}$ & $33.4^{* * *}$ & 0.2 & 1.6 & $6.7^{*}$ & 0.0 \\
\hline$V_{\mathrm{cmax}}$ & $13.7^{* * *}$ & $10.2^{* *}$ & 0.3 & 0.0 & 0.0 & 0.9 \\
\hline SLA & $46.6^{* * *}$ & $39.2^{* * *}$ & 0.0 & $14.9^{* * *}$ & 0.1 & 0.1 \\
\hline PNUE & $109.2^{* * *}$ & 0.0 & 0.8 & 2.1 & 0.0 & 0.2 \\
\hline $\mathrm{N}$ leaf & $138.0^{* * *}$ & $11.5^{* *}$ & $33.9^{* * *}$ & 1.2 & $36.2^{* * *}$ & 3.6 \\
\hline P leaf & $62.2^{* * *}$ & 0.5 & $27.5^{* * *}$ & $23.9^{* * * *}$ & 0.3 & 2.2 \\
\hline K leaf & $97.3^{* * *}$ & $244.7^{* * *}$ & $53.5^{* * *}$ & $148.6^{* * *}$ & 1.0 & $4.7^{*}$ \\
\hline $\mathrm{Chl}_{\mathrm{a}}$ & $56.9^{* * *}$ & $11.0^{* *}$ & $8.9^{* *}$ & 1.9 & $11.1^{* *}$ & 0.2 \\
\hline $\mathrm{Chl}_{\mathrm{b}}$ & $59.0^{* * *}$ & $25.9^{* * *}$ & $8.4^{* *}$ & $6.7^{*}$ & $9.7^{* *}$ & 0.6 \\
\hline Chlorophyll a/b ratio & $24.0^{* * *}$ & $52.2^{* * *}$ & $5.9^{*}$ & $6.4^{*}$ & $7.2^{*}$ & 0.2 \\
\hline Total carotenoids & $53.2^{* * *}$ & 0.4 & 1.2 & $15.4^{* * *}$ & 3.7 & $5.3^{*}$ \\
\hline Chl/carotenoid ratio & $29.1^{* * *}$ & $36.6^{* * *}$ & $23.0^{* * *}$ & $5.8^{*}$ & $19.5^{* * *}$ & $5.2^{*}$ \\
\hline
\end{tabular}

Table 2

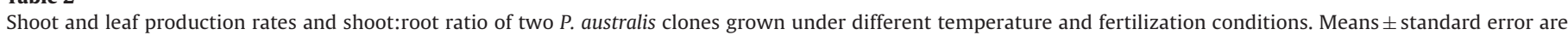
shown. ALG, Algerian clone; DK, Danish clone.

\begin{tabular}{|c|c|c|c|c|c|c|c|}
\hline \multirow[t]{2}{*}{ Temp } & \multirow[t]{2}{*}{ Fert } & \multicolumn{2}{|c|}{ Shoot production rate (shoots $\mathrm{d}^{-1}$ ) } & \multicolumn{2}{|c|}{ Leaf production rate (leaves $\mathrm{d}^{-1}$ ) } & \multicolumn{2}{|c|}{ Shoot:root ratio } \\
\hline & & DK & ALG & DK & ALG & DK & ALG \\
\hline \multirow[t]{2}{*}{$15^{\circ} \mathrm{C}$} & Low & $0.18 \pm 0.03$ & $0.12 \pm 0.01$ & $0.92 \pm 0.07$ & $1.54 \pm 0.11$ & $0.34 \pm 0.03$ & $1.85 \pm 0.14$ \\
\hline & High & $0.20 \pm 0.05$ & $0.21 \pm 0.02$ & $0.92 \pm 0.17$ & $2.21 \pm 0.10$ & $0.55 \pm 0.17$ & $2.15 \pm 0.21$ \\
\hline \multirow[t]{2}{*}{$25^{\circ} \mathrm{C}$} & Low & $0.52 \pm 0.07$ & $0.32 \pm 0.05$ & $4.38 \pm 0.63$ & $3.54 \pm 0.23$ & $2.79 \pm 0.70$ & $2.24 \pm 0.11$ \\
\hline & High & $0.76 \pm 0.10$ & $0.42 \pm 0.02$ & $5.71 \pm 0.78$ & $5.08 \pm 0.26$ & $3.47 \pm 0.12$ & $2.80 \pm 0.17$ \\
\hline
\end{tabular}

"nutrient and pigment factor". Principal component 3 (PC3) explained an additional $9.8 \%$ of the variation and had high loadings for $P_{\max }, V_{\mathrm{cmax}}, R_{\mathrm{d}}, F_{\mathrm{v}} / F_{\mathrm{m}}$ and $I_{\mathrm{c}}$; hence, it was interpreted as "photosynthesis factor". Together the three factors explained $72.9 \%$ of the variation in the measured parameters. Fig. 3 shows the distribution of the genotypes according to the experimental treatment within the first two principal components. The two clones are clearly separated from each other. Both clones were separated according to the temperature treatment along the "growth factor" (PC1) with high loadings for the High Temp treatment and low loadings for the Low Temp treatment, but the DK clone showed a much stronger distinction to the treatment with a larger separation than the ALG clone. The DK clone was not separated according to fertilization but the ALG clone had higher loadings for the High Fert treatment and lower loadings for the Low Fert treatment along the "nutrient and pigment factor" (PC2).

Table 3

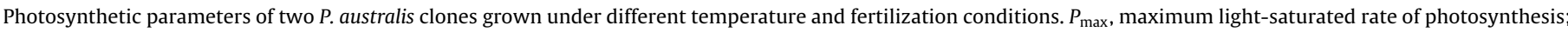


carboxylation rate; PNUE, photosynthetic nitrogen-use efficiency. Means \pm standard error are shown. ALG, Algerian clone; DK, Danish clone.

\begin{tabular}{|c|c|c|c|c|c|c|c|c|c|}
\hline \multirow[t]{2}{*}{ Temp } & \multirow[t]{2}{*}{ Fert } & \multicolumn{2}{|c|}{$P_{\max }\left(\mu \mathrm{mol} \mathrm{m}{ }^{-2} \mathrm{~s}^{-1}\right)$} & \multicolumn{2}{|c|}{$\phi\left(\mathrm{mol} \mathrm{mol}^{-1}\right)$} & \multicolumn{2}{|c|}{$R_{\mathrm{d}}\left(\mu \mathrm{mol} \mathrm{m}^{-2} \mathrm{~s}^{-1}\right)$} & \multicolumn{2}{|c|}{$I_{\mathrm{c}}\left(\mu \mathrm{mol} \mathrm{m}^{-2} \mathrm{~s}^{-1}\right)$} \\
\hline & & DK & ALG & DK & ALG & DK & ALG & DK & ALG \\
\hline \multirow[t]{2}{*}{$15^{\circ} \mathrm{C}$} & Low & $22.5 \pm 1.5$ & $21.0 \pm 1.0$ & $0.04 \pm 0.00$ & $0.03 \pm 0.00$ & $0.73 \pm 0.11$ & $0.74 \pm 0.07$ & $17.0 \pm 2.2$ & $22.9 \pm 2.3$ \\
\hline & High & $19.9 \pm 1.5$ & $28.3 \pm 0.4$ & $0.04 \pm 0.00$ & $0.04 \pm 0.00$ & $0.84 \pm 0.11$ & $1.08 \pm 0.11$ & $23.2 \pm 3.0$ & $27.2 \pm 3.9$ \\
\hline \multirow[t]{2}{*}{$25^{\circ} \mathrm{C}$} & Low & $17.3 \pm 1.8$ & $17.0 \pm 2.8$ & $0.04 \pm 0.00$ & $0.03 \pm 0.00$ & $0.59 \pm 0.09$ & $0.58 \pm 0.10$ & $15.4 \pm 3.1$ & $16.4 \pm 2.3$ \\
\hline & High & $17.3 \pm 2.0$ & $21.6 \pm 1.5$ & $0.04 \pm 0.00$ & $0.04 \pm 0.00$ & $0.65 \pm 0.13$ & $1.29 \pm 0.14$ & $14.5 \pm 2.5$ & $31.6 \pm 2.7$ \\
\hline \multirow[t]{2}{*}{ Temp } & Fert & \multicolumn{2}{|c|}{$\Gamma\left(\mu \mathrm{mol} \mathrm{m}^{-2} \mathrm{~s}^{-1}\right)$} & \multicolumn{2}{|l|}{$F_{\mathrm{v}} / F_{\mathrm{m}}$} & \multicolumn{2}{|c|}{$V_{\mathrm{cmax}}\left(\mu \mathrm{mol} \mathrm{m}^{-2} \mathrm{~s}^{-1}\right)$} & \multicolumn{2}{|c|}{ PNUE $\left(\mu \mathrm{mol} \mathrm{CgN}{ }^{-1} \mathrm{~s}^{-1}\right)$} \\
\hline & & DK & ALG & DK & ALG & DK & ALG & DK & ALG \\
\hline \multirow[t]{2}{*}{$15^{\circ} \mathrm{C}$} & Low & $51.1 \pm 3.7$ & $55.2 \pm 1.2$ & $0.75 \pm 0.02$ & $0.68 \pm 0.01$ & $55.9 \pm 9.7$ & $37.6 \pm 3.3$ & $11.0 \pm 0.6$ & $18.8 \pm 1.0$ \\
\hline & High & $48.3 \pm 3.0$ & $55.6 \pm 1.5$ & $0.71 \pm 0.02$ & $0.72 \pm 0.01$ & $56.7 \pm 9.8$ & $40.3 \pm 3.0$ & $10.6 \pm 0.9$ & $18.7 \pm 1.9$ \\
\hline \multirow[t]{2}{*}{$25^{\circ} \mathrm{C}$} & Low & $71.1 \pm 1.7$ & $69.6 \pm 3.5$ & $0.78 \pm 0.01$ & $0.76 \pm 0.01$ & $72.9 \pm 3.9$ & $57.8 \pm 8.9$ & $10.3 \pm 0.6$ & $21.9 \pm 3.1$ \\
\hline & High & $72.3 \pm 1.3$ & $69.7 \pm 3.9$ & $0.77 \pm 0.01$ & $0.78 \pm 0.01$ & $67.0 \pm 3.1$ & $50.4 \pm 5.9$ & $9.6 \pm 0.9$ & $19.9 \pm 1.8$ \\
\hline
\end{tabular}


Table 4


fertilization conditions. Means \pm standard error are shown. ALG, Algerian clone; DK, Danish clone.

\begin{tabular}{|c|c|c|c|c|c|c|c|}
\hline \multirow[t]{2}{*}{ Temp } & \multirow[t]{2}{*}{ Fert } & \multicolumn{2}{|c|}{$\mathrm{Chl}_{\mathrm{a}}\left(\mathrm{mg} \mathrm{g}^{-1} \mathrm{DM}\right)$} & \multicolumn{2}{|c|}{$\mathrm{Chl}_{\mathrm{b}}\left(\mathrm{mgg}^{-1} \mathrm{DM}\right)$} & \multicolumn{2}{|c|}{ Chlorophyll a/b ratio } \\
\hline & & DK & ALG & DK & ALG & DK & ALG \\
\hline \multirow[t]{2}{*}{$15^{\circ} \mathrm{C}$} & Low & $4.55 \pm 0.40$ & $1.78 \pm 0.16$ & $1.10 \pm 0.11$ & $0.40 \pm 0.04$ & $4.16 \pm 0.07$ & $4.55 \pm 0.17$ \\
\hline & High & $3.84 \pm 0.24$ & $3.68 \pm 0.27$ & $0.92 \pm 0.07$ & $0.88 \pm 0.07$ & $4.21 \pm 0.06$ & $4.19 \pm 0.07$ \\
\hline \multirow[t]{2}{*}{$25^{\circ} \mathrm{C}$} & Low & $5.11 \pm 0.42$ & $2.62 \pm 0.24$ & $1.51 \pm 0.15$ & $0.63 \pm 0.06$ & $3.43 \pm 0.09$ & $4.22 \pm 0.13$ \\
\hline & High & $5.60 \pm 0.28$ & $3.77 \pm 0.46$ & $1.65 \pm 0.10$ & $1.02 \pm 0.15$ & $3.42 \pm 0.09$ & $3.78 \pm 0.14$ \\
\hline \multirow[t]{2}{*}{ Temp } & Fert & \multicolumn{2}{|c|}{ Chl/carotenoid ratio } & \multicolumn{2}{|c|}{ Total carotenoids ( $\mathrm{mg} \mathrm{g}^{-1} \mathrm{DM}$ ) } & \multicolumn{2}{|c|}{$\mathrm{SLA}\left(\mathrm{m}^{2} \mathrm{~kg}^{-1} \mathrm{DM}\right)$} \\
\hline & & DK & ALG & DK & ALG & DK & ALG \\
\hline \multirow[t]{2}{*}{$15^{\circ} \mathrm{C}$} & Low & $4.01 \pm 0.18$ & $2.06 \pm 0.19$ & $1.40 \pm 0.08$ & $1.06 \pm 0.03$ & $14.7 \pm 0.5$ & $16.0 \pm 0.5$ \\
\hline & High & $4.08 \pm 0.18$ & $3.91 \pm 0.24$ & $1.16 \pm 0.03$ & $1.17 \pm 0.06$ & $14.7 \pm 0.3$ & $15.9 \pm 0.4$ \\
\hline \multirow[t]{2}{*}{$25^{\circ} \mathrm{C}$} & Low & $4.55 \pm 0.11$ & $3.81 \pm 0.20$ & $1.44 \pm 0.10$ & $0.85 \pm 0.06$ & $15.8 \pm 0.6$ & $20.0 \pm 1.1$ \\
\hline & High & $4.57 \pm 0.07$ & $4.49 \pm 0.24$ & $1.59 \pm 0.08$ & $1.05 \pm 0.09$ & $15.6 \pm 0.5$ & $20.4 \pm 0.6$ \\
\hline
\end{tabular}

Table 5

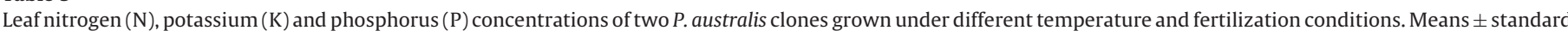
error are shown. ALG, Algerian clone; DK, Danish clone.

\begin{tabular}{|c|c|c|c|c|c|c|c|}
\hline \multirow[t]{2}{*}{ Temp } & \multirow[t]{2}{*}{ Fert } & \multicolumn{2}{|l|}{ N leaf (\% DM) } & \multicolumn{2}{|c|}{ P leaf (mg g $\left.{ }^{-1} \mathrm{DM}\right)$} & \multicolumn{2}{|c|}{$\mathrm{K}$ leaf $\left(\mathrm{mg} \mathrm{g}^{-1} \mathrm{DM}\right)$} \\
\hline & & DK & ALG & DK & ALG & DK & ALG \\
\hline \multirow[t]{2}{*}{$15^{\circ} \mathrm{C}$} & Low & $2.99 \pm 0.05$ & $1.79 \pm 0.06$ & $2.7 \pm 0.1$ & $2.3 \pm 0.1$ & $20.4 \pm 1.1$ & $21.4 \pm 0.8$ \\
\hline & High & $2.78 \pm 0.20$ & $2.48 \pm 0.17$ & $2.9 \pm 0.3$ & $2.7 \pm 0.1$ & $23.3 \pm 1.9$ & $26.0 \pm 0.6$ \\
\hline \multirow[t]{2}{*}{$25^{\circ} \mathrm{C}$} & Low & $2.59 \pm 0.09$ & $1.51 \pm 0.03$ & $2.8 \pm 0.1$ & $1.8 \pm 0.1$ & $37.9 \pm 1.5$ & $23.9 \pm 0.7$ \\
\hline & High & $2.78 \pm 0.06$ & $2.23 \pm 0.08$ & $3.4 \pm 0.1$ & $2.3 \pm 0.1$ & $47.2 \pm 0.3$ & $28.6 \pm 0.4$ \\
\hline
\end{tabular}

Plasticity indices (PIs) were affected by a significant Clone $\times$ Treatment interaction $(P<0.05 ; F$-ratio $=5.86)$. Treatment had no effect on PIs of the ALG clone, whereas PIs were higher in the temperature treatment than in the fertilization

Table 6

Equimax-rotated principal component analysis (PCA) of all measured and analyzed parameters of two $P$. australis clones grown at different temperature and fertilization conditions. Variables with high loadings are shown in bold. SLA, specific leaf area; $\Gamma, \mathrm{CO}_{2}$ compensation point; PNUE, photosynthetic nitrogen-use efficiency; $\phi$, apparent quantum yield; $P_{\max }$, maximum light-saturated rate of photosynthesis; $R_{\mathrm{d}}$, dark respiration rate; $I_{\mathrm{c}}$, light compensation point; $V_{\mathrm{cmax}}$, maximum carboxylation rate of Rubisco; $F_{\mathrm{v}} / F_{\mathrm{m}}$, effective quantum yield of PSII.

\begin{tabular}{|c|c|c|c|}
\hline & PC 1 & PC 2 & PC 3 \\
\hline Eigenvalue & 9.1 & 6.7 & 2.4 \\
\hline Proportion of variance (\%) & 36.4 & 26.7 & 9.8 \\
\hline Cumulative proportion of variance (\%) & 36.4 & 63.1 & 72.9 \\
\hline \multicolumn{4}{|l|}{ Variable } \\
\hline Shoot production rate & 0.726 & 0.436 & -0.290 \\
\hline Leaf production rate & 0.939 & 0.124 & -0.137 \\
\hline Shoot:root ratio & 0.896 & 0.096 & -0.043 \\
\hline Leaf blade allocation & 0.862 & 0.331 & -0.270 \\
\hline Leaf sheath allocation & 0.810 & -0.178 & 0.155 \\
\hline Root allocation & -0.922 & 0.059 & -0.110 \\
\hline Rhizome allocation & -0.933 & 0.073 & 0.019 \\
\hline SLA & 0.551 & -0.381 & 0.105 \\
\hline$\Gamma$ & 0.796 & 0.106 & -0.216 \\
\hline K leaf & 0.631 & 0.591 & -0.285 \\
\hline $\mathrm{Chl}_{\mathrm{a}}$ & 0.117 & 0.935 & -0.182 \\
\hline $\mathrm{Chl}_{\mathrm{b}}$ & 0.252 & 0.904 & -0.237 \\
\hline Chlorophyll a/b ratio & -0.481 & -0.701 & 0.245 \\
\hline Total carotenoids & -0.028 & 0.839 & -0.219 \\
\hline Chl/carotenoid ratio & 0.264 & 0.743 & -0.065 \\
\hline $\mathrm{N}$ leaf & -0.328 & 0.865 & 0.012 \\
\hline P leaf & 0.038 & 0.734 & -0.110 \\
\hline PNUE & 0.236 & -0.586 & 0.523 \\
\hline Stem allocation & 0.550 & -0.643 & 0.407 \\
\hline$\phi$ & -0.056 & 0.696 & 0.167 \\
\hline$P_{\max }$ & -0.237 & 0.152 & 0.672 \\
\hline$R_{\mathrm{d}}$ & 0.075 & 0.099 & 0.892 \\
\hline$I_{\mathrm{C}}$ & 0.034 & -0.154 & 0.821 \\
\hline$V_{\text {cmax }}$ & 0.074 & 0.349 & -0.527 \\
\hline$F_{\mathrm{v}} / F_{\mathrm{m}}$ & 0.363 & 0.345 & -0.378 \\
\hline
\end{tabular}

treatment for the DK clone. "Treatment" was a significant main effect $(P<0.01 ; F$-ratio $=8.88)$ with the highest PIs for temperature. Overall, PIs for parameters related to biomass and growth were highest, especially for the DK clone (Table 7). On average, although not significant, the DK clone had the highest PIs for temperature and the ALG clone had the highest PIs for fertilization (Table 7). The highest plasticity of the DK clone was found for biomass and growth parameters, the temperature response being dominant. For the ALG clone, the highest plasticity was found for photosynthetic parameters and pigments as a response mainly to fertilization (Fig. 4).

To identify which of the parameters were mostly related to fitness at the different growth conditions, the "fitness factor" scores were used as independent variables together with all parameters to generate Pearson product moment correlations $(r)$ to assess the

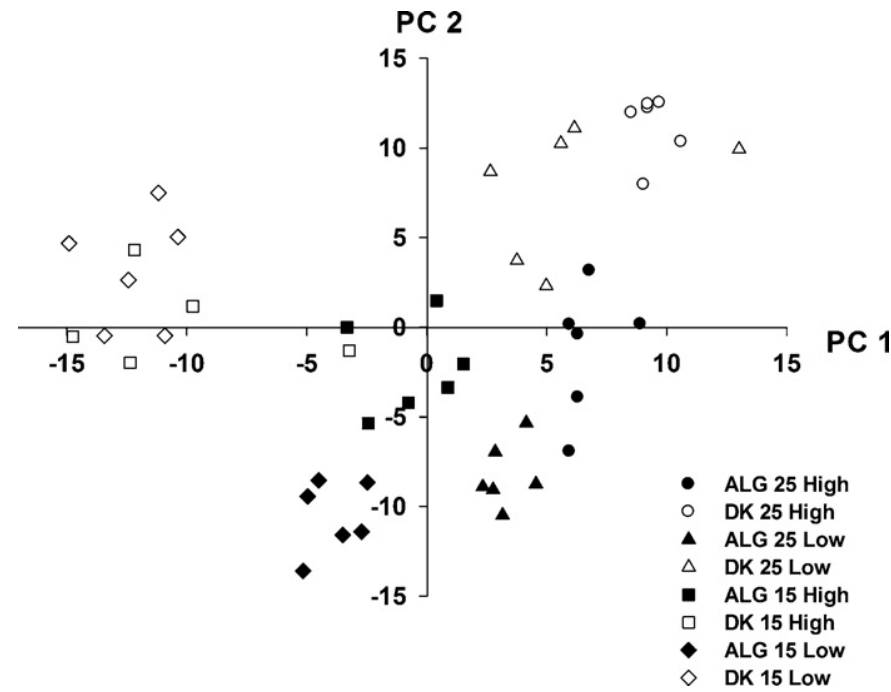

Fig. 3. Factor scores of $P C 1$ plotted against $P C 2$ of PCA of measured parameters in two distinct genotypes of $P$. australis (DK, DK clone; ALG, ALG clone) grown at $15^{\circ} \mathrm{C}$ and $25^{\circ} \mathrm{C}$ and at low and high fertilization, respectively. 
Table 7

Plasticity Indices (PIs) for traits of two P. australis clones grown under different temperature and fertilization conditions. $P_{\max }$, maximum light-saturated rate of photosynthesis; $R_{\mathrm{d}}$, dark respiration rate; $\phi$, apparent quantum yield; $I_{\mathrm{c}}$, light compensation point; $\Gamma, \mathrm{CO}_{2}$ compensation point; $F_{\mathrm{v}} / F_{\mathrm{m}}$, effective quantum yield of PSII; $V_{\mathrm{cmax}}$, maximum carboxylation rate of Rubisco; SLA, specific leaf area; PNUE, photosynthetic nitrogen-use efficiency. DK, DK clone; ALG, ALG clone.

\begin{tabular}{|c|c|c|c|c|}
\hline \multirow[t]{2}{*}{ Variable } & \multicolumn{2}{|c|}{ PI temperature } & \multicolumn{2}{|c|}{ PI fertilization } \\
\hline & DK & ALG & DK & ALG \\
\hline Shoot production rate & 0.71 & 0.55 & 0.31 & 0.29 \\
\hline Leaf production rate & 0.82 & 0.57 & 0.25 & 0.30 \\
\hline Shoot:root ratio & 0.86 & 0.21 & 0.27 & 0.17 \\
\hline Leaf blade allocation & 0.70 & 0.27 & 0.14 & 0.13 \\
\hline Leaf sheath allocation & 0.49 & 0.08 & 0.20 & 0.06 \\
\hline Stem allocation & 0.47 & 0.01 & 0.19 & 0.00 \\
\hline Rhizome allocation & 0.56 & 0.19 & 0.18 & 0.07 \\
\hline$P_{\max }$ & 0.19 & 0.22 & 0.07 & 0.24 \\
\hline$R_{\mathrm{d}}$ & 0.20 & 0.03 & 0.11 & 0.44 \\
\hline$\phi$ & 0.03 & 0.00 & 0.02 & 0.19 \\
\hline$I_{\mathrm{c}}$ & 0.25 & 0.04 & 0.12 & 0.33 \\
\hline$\Gamma$ & 0.31 & 0.20 & 0.01 & 0.00 \\
\hline$F_{\mathrm{v}} / F_{\mathrm{m}}$ & 0.05 & 0.09 & 0.02 & 0.04 \\
\hline$V_{\mathrm{cmax}}$ & 0.20 & 0.28 & 0.03 & 0.05 \\
\hline SLA & 0.06 & 0.21 & 0.00 & 0.01 \\
\hline $\mathrm{Chl}_{\mathrm{a}}$ & 0.21 & 0.15 & 0.01 & 0.41 \\
\hline $\mathrm{Chl}_{\mathrm{b}}$ & 0.36 & 0.22 & 0.01 & 0.46 \\
\hline $\mathrm{Chl}$ a/b ratio & 0.18 & 0.08 & 0.00 & 0.09 \\
\hline PNUE & 0.08 & 0.10 & 0.06 & 0.05 \\
\hline N leaf & 0.07 & 0.12 & 0.01 & 0.30 \\
\hline P leaf & 0.72 & 0.17 & 0.71 & 0.18 \\
\hline
\end{tabular}

functional significance of the individual parameters. Fitness of the DK clone correlated positively with leaf blade allocation $(r=0.894)$, leaf sheath allocation $(r=0.706)$, stem allocation $(r=0.767)$ the shoot:root ratio $(r=0.774)$, shoot production rate $(r=0.948)$, leaf production rate $(r=0.968)$, leaf P content $(r=0.516), \mathrm{Chl}_{\mathrm{a}}(r=0.479)$, $\mathrm{Chl}_{\mathrm{b}}(r=0.651), F_{\mathrm{v}} / F_{\mathrm{m}}(r=0.434)$ and $\Gamma(r=0.808) . P_{\max }(r=-0.523)$, biomass allocation to rhizomes $(r=-0.820)$ and the $\mathrm{Chl}$ a/b ratio

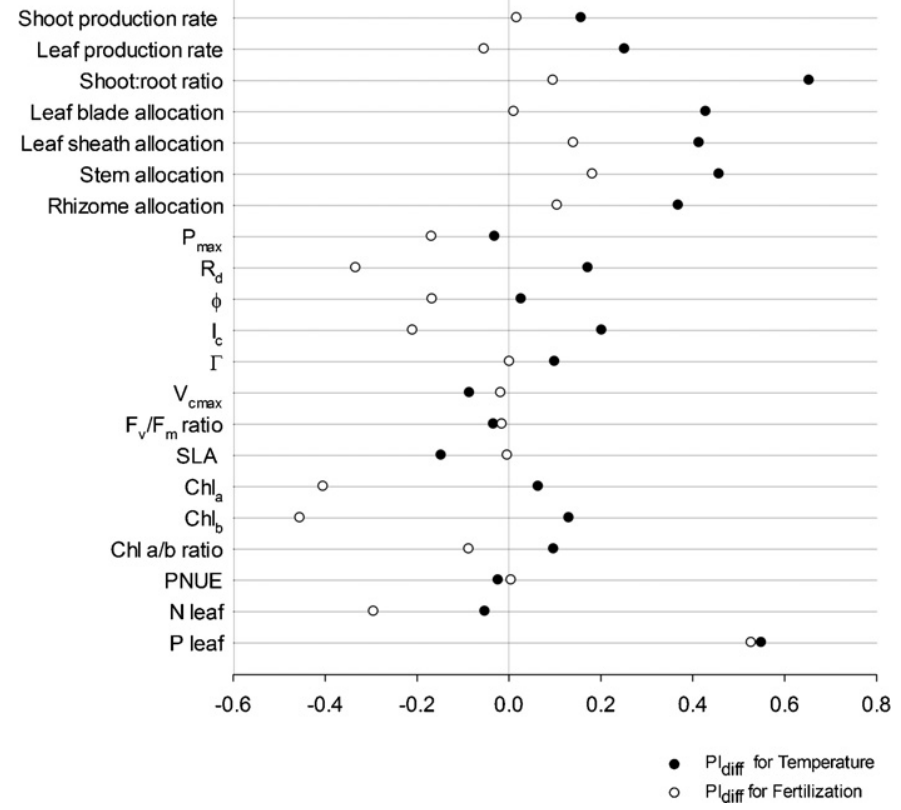

Fig. 4. Differences of plasticity indices $\left(\mathrm{PI}_{\mathrm{diff}}: \mathrm{PI}_{\mathrm{DK}}-\mathrm{PI}_{\mathrm{ALG}}\right)$ of measured parameters in two distinct genotypes of $P$. australis grown at different temperatures and nutrient availability. $\mathrm{PI}_{\text {diff }}>0$ are highest for the DK clone; $\mathrm{PI}_{\text {diff }}<0$ are highest for the ALG clone. $P_{\max }$, maximum light-saturated rate of photosynthesis; $R_{\mathrm{d}}$, dark respiration rate; $\phi$, apparent quantum yield; $I_{\mathrm{c}}$, light compensation point; $\Gamma, \mathrm{CO}_{2}$ compensation point; $V_{\mathrm{cmax}}$, maximum carboxylation rate of Rubisco; $F_{\mathrm{v}} / F_{\mathrm{m}}$, effective quantum yield of PSII; SLA, specific leaf area; PNUE, photosynthetic nitrogen-use efficiency. $(r=-0.834)$ correlated negatively with fitness of the DK clone. For the ALG clone, fitness correlated positively with biomass allocation to leaf blades $(r=0.533)$, the shoot:root ratio $(r=0.634)$, shoot production rate $(r=0.625)$, leaf production rate $(r=0.674), \mathrm{Chl}_{\mathrm{a}}$ $(r=0.469)$, $\mathrm{Chl}_{\mathrm{b}}(r=0.479), R_{\mathrm{d}}(r=0.537)$ and $I_{\mathrm{C}}(r=0.418)$, and negatively with biomass allocation to rhizomes $(r=-0.459)$ and the Chl a/b ratio $(r=-0.549)$.

\section{Discussion}

The responses of the two genotypes of $P$. australis originating from contrasting climatic areas to temperature and fertilization level differed significantly. Overall, the DK clone responded mostly to temperature, whereas the ALG clone responded mostly to fertilization.

Both clones responded to high fertilization with higher aboveground and lower belowground biomass allocation. Also Bastlova et al. (2004) showed a positive relationship of nutrient-dose and aboveground biomass for different populations of $P$. australis. Under nutrient-poor conditions plants commonly increase relative allocation to rhizomes and roots to increase the nutrient-uptake capacity and storage (Chapin et al., 1987). It is striking that the DK clone has a higher biomass in the Low Temp/Low Fert treatment compared to the Low Temp/High Fert treatment. However, this is not a statistically significant difference and can be attributed mainly to the high and probably faster allocation to belowground biomass, especially rhizomes. Also, the slightly higher photosynthetic parameters such as $\mathrm{Chl}_{\mathrm{a}+\mathrm{b}}, P_{\max }, F_{\mathrm{v}} / F_{\mathrm{m}}$, PNUE and the low $I_{\mathrm{c}}$ point to a more efficient photosynthesis of the DK clone at low temperature and low fertilization.

The physiological parameters measured for the DK and the ALG clone were within the range previously reported for different populations of $P$. australis (Hansen et al., 2007). Photosynthetic parameters of the ALG clone, such as $F_{\mathrm{v}} / F_{\mathrm{m}}, P_{\max }$ and $R_{\mathrm{d}}$ responded positively to high fertilization, suggesting a nutrient limitation for those parameters in the ALG clone. Plants grown at high nutrient availability have been reported to have high photosynthetic activity and high dark respiration rates due to the high construction and maintenance requirements of leaves containing more nitrogen (Chapin et al., 1987). Nitrogen is one of the nutrients most frequently limiting plant growth. Most nitrogen in plant leaves is invested in compounds involved in photosynthesis, and at limited $\mathrm{N}$ supply, a relatively larger proportion of the overall smaller $\mathrm{N}$ pool is invested in non-photosynthetic compounds (Chapin et al., 1987). Also photosynthetic pigments of the ALG clone were higher after growth at the high fertilization level. This is consistent with the findings of Lippert et al. (2001), who related the higher $\mathrm{N}$ availability to higher chlorophyll contents in a $P$. australis stand from a eutrophic lake, compared to a stand from a mesotrophic area.

Compared to the DK clone, the ALG clone showed characteristics of leaves exposed to more light, such as a lower pigment concentrations per leaf mass, lower $\mathrm{Chl} /$ carotenoid and higher $\mathrm{Chl} \mathrm{a} / \mathrm{b}$ ratios. The leaves used for the analyses probably received a slightly higher irradiance due to the taller shoots of the ALG clone being closer to the light source. Nevertheless, the high PNUE and SLA of the ALG clone point to a more efficient photosynthesis and inherently faster growth rates, which can explain the clone's high demand for nutrients. The DK clone did not respond similarly to increased nutrient availability, suggesting that its nutrient demand was much lower, probably due to inherently slower growth rates.

Increased temperatures within the normal physiological temperature range generally accelerate biochemical and physiological processes, which stimulates plant growth (Atkin et al., 2006). Previous studies have shown that high temperatures also affect 
flowering and stimulate biomass production in several plant species (Richardson et al., 2002; Werkman and Callaghan, 2002). However, temperature may also interact with nutrient availability. Since high temperatures enhance transpiration, the mass flow of water, containing dissolved ions, increases simultaneously from the bulk soil to the plant roots. In addition, high temperatures accelerate decomposition and mineralization processes in the soil (Chapin et al., 1988). Therefore, a rise in temperature may indirectly promote plant growth by increasing nutrient availability. However, if plant nutrient demands are not met, increased temperature might not have the expected effect on plant biomass. In the present study, the High Temp treatment favored growth of the DK clone also under low nutrient availability, suggesting a lower nutrient demand for the DK clone than that for the ALG clone. Furthermore, the considerably higher final biomass of the ALG clone implies faster growth rates and therefore a lower threshold for $\mathrm{N}$-limitation than the DK clone. In low-temperature areas at high latitudes, such as Denmark, soil nutrient cycling proceeds slowly. Hence, plants adapted to these areas may be inherently more tolerant to low nutrient availability. It has been postulated that the genetic variation in $P$. australis has arisen analogously to the latitude of its geographical origin. In a common garden experiment of $P$. australis populations from different geographical areas, Lessmann et al. (2001) found that photosynthetic characteristics were highly affected by the climate at the growth site as well as the climate of the population origin. Clevering et al. (2001) found considerable genotypic differences in growth characteristics, SLA and number and morphology of shoots of $P$. australis clones, which could be related to the climate at the clone's location of origin. More northern populations started to grow earlier and had longer growth periods, produced more but shorter shoots and invested less biomass in seedling stems than southern populations. Also, Bastlova et al. (2006) found a negative correlation of latitude of origin with plant height and biomass and a positive correlation with SLA of $P$. australis originating from localities across a geographical gradient. This is in agreement with the present study, where the ALG clone, which can be considered a southern population, had a higher biomass, fewer but taller shoots and a higher SLA than the DK clone. Both clones displayed plasticity in most investigated traits. This is in accordance with other studies investigating phenotypic plasticity in $P$. australis. Lessmann et al. (2001) and Clevering et al. (2001) found plastic responses in photosynthetic characteristics, biomass allocation and RGR of genotypes grown at different climatic conditions, and Vretare et al. (2001) reported that $P$. australis exhibited functional plasticity as a response to water depth. However, trait plasticity is not always adaptive as the trait must correlate with plant performance to contribute to fitness (Dudley, 2004; Sultan, 1995). In this study, we used a biomassbased parameter as a proxy for fitness. Especially for a clonal and highly productive plant like $P$. australis that is largely spreading by vegetative growth, biomass is an adequate measure of plant performance and fitness. In both clones, photosynthetic pigments, biomass allocation to leaf blades and rhizomes, the shoot:root ratio as well as leaf and shoot production rates were highly correlated to fitness. These traits also had a relatively high degree of plasticity (PI larger than 0 ), indicating that high phenotypic plasticity in these traits increased fitness. However, some traits that showed high plasticity did not correlate with fitness (e.g. $P_{\max }$ and $\mathrm{P}$ content of leaves in the ALG clone). Rather few traits that correlated strongly with fitness had very low plasticity (e.g. $F_{\mathrm{v}} / F_{\mathrm{m}}$ in the DK clone and the $\mathrm{Chl} \mathrm{a} / \mathrm{b}$ ratio). This supports the idea that even small differences in the plasticity of certain traits can have far-reaching consequences for fitness (Funk, 2008; Givnish, 2002). The lack of functional significance of traits important for resource scavenging and conservation, such as SLA, PNUE and $\phi$, may be due to the fact that we measured fitness on a relatively short timescale. These traits may be of importance for fitness if evaluated over several growth seasons.

In conclusion, this study shows that the responses of the two $P$. australis genotypes from contrasting geographical regions to temperature and fertilization are largely genetically determined and can be related to the climatic conditions at the site of their origin. The correlations of the measured traits with fitness suggest that the plasticity of several ecophysiological traits influenced plant performance. We suggest that the great success of $P$. australis over a variety of contrasting geographic regions and habitats is promoted by its high degree of phenotypic plasticity in response to different environmental conditions. Differences in phenotypic plasticity of distinct $P$. australis genotypes play a substantial role in fitness responses to temperature and nutrient availability and will influence how these genotypes will respond to changing environmental conditions.

\section{Acknowledgements}

This research was funded by the Danish Council for Independent Research - Natural Sciences, and Aarhus Graduate School of Science.

\section{References}

Atkin, O.K., Loveys, B.R., Atkinson, L.J., Pons, T.L., 2006. Phenotypic plasticity and growth temperature: understanding interspecific variability. Journal of Experimental Botany 57, 267-281.

Bastlova, D., Bastl, M., Cizkova, H., Kvet, J., 2006. Plasticity of Lythrum salicaria and Phragmites australis growth characteristics across a European geographical gradient. Hydrobiologia 570, 237-242.

Bastlova, D., Cizkova, H., Bastl, M., Kvet, J., 2004. Growth of Lythrum salicaria and Phragmites australis plants originating from a wide geographical area: response to nutrient and water supply. Global Ecology and Biogeography 13, 259-271.

Bellavance, M., Brisson, J., 2010. Spatial dynamics and morphological plasticity of common reed (Phragmites australis) and cattails (Typha sp.) in freshwater marshes and roadside ditches. Aquatic Botany 93, 129-134.

Bradshaw, A.D., 1965. Evolutionary significance of phenotypic plasticity in plants. Advances in Genetics 13, 115-155.

Brix, H., 1999. Genetic diversity, ecophysiology and growth dynamics of reed (Phragmites australis) - introduction. Aquatic Botany 64, 179-184.

Chapin, F.S., Bloom, A.J., Field, C.B., Waring, R.H., 1987. Plant responses to multiple environmental factors. BioScience 37, 49-57.

Chapin, F.S., Fetcher, N., Kielland, K., Everett, K.R., Linkins, A.E., 1988. Productivity and nutrient cycling of Alaskan tundra: enhancement by flowing soil water. Ecology 69, 693-702.

Clevering, O.A., 1999. The effects of litter on growth and plasticity of Phragmites australis clones originating from infertile, fertile or eutrophicated habitats. Aquatic Botany 64, 35-50.

Clevering, O.A., Brix, H., Lukavska, J., 2001. Geographic variation in growth responses in Phragmites australis. Aquatic Botany 69, 89-108.

Clevering, O.A., Lissner, J., 1999. Taxonomy, chromosome numbers, clonal diversity and population dynamics of Phragmites australis. Aquatic Botany 64, 185-208.

Coleman, J.S., McConnaughay, K.D.M., Ackerly, D.D., 1994. Interpreting phenotypic variation in plants. Trends in Ecology and Evolution 9, 187-191.

Dong, M., During, H.J., Werger, M.J.A., 1996. Morphological responses to nutrient availability in four clonal herbs. Vegetatio 123, 183-192.

Dubois, J.J.B., Fiscus, E.L., Booker, F.L., Flowers, M.D., Reid, C.D., 2007. Optimizing the statistical estimation of the parameters of the Farquhar-von Caemmerer-Berry model of photosynthesis. New Phytologist 176, 402-414.

Dudley, S.A., 2004. The functional ecology of phenotypic plasticity in plants. In DeWitt, T.J., Scheiner, S.M. (Eds.), Phenotypic Plasticity. Functional and Conceptual Approaches. Oxford University Press, New York, pp. 151-172.

Engloner, A.I., 2009. Structure, growth dynamics and biomass of reed (Phragmites australis) - a review. Flora 204, 331-346.

Equiza, M.A., Tognetti, J.A., 2002. Morphological plasticity of spring and winter wheats in response to changing temperatures. Functional Plant Biology 29, 1427-1436.

Farquhar, G.D., Caemmerer, S.V., Berry, J.A., 1980. A biochemical model of photosynthetic $\mathrm{CO}_{2}$ assimilation in leaves of $\mathrm{C} 3$ species. Planta 149, 78-90.

Funk, J., 2008. Differences in plasticity between invasive and native plants from a low resource environment. Journal of Ecology 96, 1162-1173.

Givnish, T.J., 2002. Ecological constraints on the evolution of plasticity in plants. Evolutionary Ecology 16, 213-242.

Grime, J.P., Mackey, J.M.L., 2002. The role of plasticity in resource capture by plants. Evolutionary Ecology 16, 299-307. 
Hansen, D.L., Lambertini, C., Jampeetong, A., Brix, H., 2007. Clone-specific differences in Phragmites australis: effects of ploidy level and geographic origin. Aquatic Botany 86, 269-279.

Haraguchi, A., 1993. Phenotypic and phenological plasticity of an aquatic macrophyte Menyanthes trifoliata l. Journal of Plant Research 106, 31-35.

Haslam, S.M., 1968. Stem types of Phragmites communis Trin. Annals of Botany 33, $127-131$.

Jonsdottir, I.S., Khitun, O., Stenstrom, A., 2005. Biomass and nutrient responses of a clonal tundra sedge to climate warming. Canadian Journal of Botany 83, 1608-1621.

Kuhl, H., Koppitz, H., Rolletschek, H., Kohl, J.G., 1999. Clone specific differences in a Phragmites australis stand I. Morphology, genetics and site description. Aquatic Botany 64, 235-246.

Lambertini, C., Gustafsson, M.H.G., Frydenberg, J., Lissner, J., Speranza, M., Brix, H., 2006. A phylogeographic study of the cosmopolitan genus Phragmites (Poaceae) based on AFLPs. Plant Systematics and Evolution 258, $161-182$.

Lehmann, C., Rebele, F., 2005. Phenotypic plasticity in Calamagrostis epigejos (Poaceae): response capacities of genotypes from different populations of contrasting habitats to a range of soil fertility. Acta Oecologica 28, 127-140.

Lessmann, J.M., Brix, H., Bauer, V., Clevering, O.A., Comin, F.A., 2001. Effect of climatic gradients on the photosynthetic responses of four Phragmites australis populations. Aquatic Botany 69, 109-126.

Lichtenthaler, H.K., 1987. Chlorophylls and carotenoids - pigments of photosynthetic biomembranes. Methods in Enzymology 148, 350-382.
Lippert, I., Rolletschek, H., Kohl, J.G., 2001. Photosynthetic pigments and efficiencies of two Phragmites australis stands in different nitrogen availabilities. Aquatic Botany 69, 359-365.

Richardson, S.J., Press, M.C., Parsons, A.N., Hartley, S.E., 2002. How do nutrients and warming impact on plant communities and their insect herbivores? A 9-year study from a sub-Arctic heath. Journal of Ecology 90, 544-556.

Rolletschek, H., Rolletschek, A., Kuhl, H., Kohl, J.G., 1999. Clone specific differences in a Phragmites australis stand II. Seasonal development of morphological and physiological characteristics at the natural site and after transplantation. Aquatic Botany 64, 247-260.

Santamaria, L., 2002. Why are most aquatic plants widely distributed? Dispersal, clonal growth and small-scale heterogeneity in a stressful environment. Acta Oecologica 23, 137-154.

Sultan, S.E., 2000. Phenotypic plasticity for plant development, function and life history. Trends in Plant Science 5, 537-542.

Sultan, S.E., 1995. Phenotypic plasticity and plant adaptation. Acta Botanica Neerlandica 44, 363-383.

Valladares, F., Sanchez-Gomez, D., Zavala, M.A., 2006. Quantitative estimation of phenotypic plasticity: bridging the gap between the evolutionary concept and its ecological applications. Journal of Ecology 94, 1103-1116.

Vretare, V., Weisner, S.E.B., Strand, J.A., Graneli, W., 2001. Phenotypic plasticity in Phragmites australis as a functional response to water depth. Aquatic Botany 69 , 127-145.

Werkman, B.R., Callaghan, T.V., 2002. Responses of bracken and heather to increased temperature and nitrogen addition, alone and in competition. Basic and Applied Ecology 3, 267-276. 